\title{
0 Cenário de mudanças globais na publicidade e o conceito de cadeia produtiva aplicado ao mercado mineiro
}

Global change scenario in advertising and the concept of productive chain applied to Minas Gerais market

\author{
Janaina Maquiaveli Cardoso \\ Professora da FESBH e Mestre em Sociologia pela UFMG \\ Letícia Lins, Luciana de Oliveira \\ Professora da FESBH , Coordenadora do curso de Publicidade e Propaganda, Publicitária, Mestre \\ em Comunicação Social pela UFMG \\ Luciana de Oliveira \\ Professora da FESBH, Publicitária, Doutoranda em Sociologia pela UFMG \\ Vanice Guedes \\ Professora da FESBH, Coordenadora da PROSA Agência Experimental de Publicidade, Publicitária, \\ Especialista em Comunicação Empresarial pela PUC-MG \\ Waldiane Fialho \\ Professora da FESBH e do Centro Universitário de Belo Horizonte - UNI-BH, Publicitária, Mestre \\ em Artes Visuais pela UFMG \\ E-mail:waldiane@bh.estacio.br
}

\section{Resumo}

Com os processos de globalização intensificados desde o início dos anos 90, a Publicidade tem passado por transformações profundas, geradas a partir das mudanças sociais, políticas, econômicas e culturais ocorridas na contemporaneidade, descortinando, atualmente, um cenário com articulações de negócios muito particulares. Nesse panorama, o conceito de cadeia produtiva apresenta-se pertinente para estabelecer as inter-relações entre os diversos agentes envolvidos na produção publicitária. Os objetivos desse artigo são contextualizar as transformações ocorridas, recentemente, na Publicidade nacional, apresentar a utilização do conceito de cadeia produtiva e suas contribuições para o fazer publicitário, além de mostrar as ações institucionais e de mercado que Minas Gerais vem realizando com o intuito de se adequar aos novos tempos da Publicidade no Brasil e no mundo.

Palavras-chave: Publicidade; Propaganda; Mercado Publicitário; Cadeia Produtiva; Publicidade Mineira.

0 cenário contemporâneo da Publicidade e suas transformações

As profundas mudanças e transformações ocorridas nos cenários sociais, políticos, econômicos e culturais mundiais vêm impulsionando importantes alterações na paisagem da publicidade nacional e internacional, exigindo do fazer publicitário novas e permanentes reconfigurações. Com os processos de globalização acirrados desde os anos 90, empresas e produtos de diferentes nacionalidades passaram a concorrer entre si na preferência dos consumidores. Os produtos tornaram-se cada vez mais 
similares em termos de preço e qualidade. Blocos econômicos internacionais se formaram. Para sobreviver nesse mundo globalizado, parcerias, aquisições, fusões ou formas alternativas de obtenção de know-how se estruturaram, ampliando o espaço para protecionismos e cartéis. Com esse panorama, a desregulamentação passou a operar e a lei de regência das negociações veio a ser a lei do mercado.

Logo, competir com empresas de todo o mundo começou a exigir aperfeiçoamento constante e a necessidade de acesso a novas tecnologias diferenciadas e de vanguarda. Paralelamente a isso, assistiu-se em nível nacional à estabilização da economia, operando com taxas inflacionárias de no máximo três a cinco por cento ao ano.

Neste cenário cada vez mais competitivo e com margens de lucro cada vez menores, foi necessário que as empresas passassem a rever suas estruturas, planejando ações, tais como: o aumento da rentabilidade e da produtividade, o reforço estratégico e a melhoria de índices de balanço e de crescimento. Das agências de publicidade, em especial, também passaram a ser exigidas revisões em suas estruturas de furcionamento, no sentido de melhorar o atendimento e as ações de comunicação, otimizar os resultados e reduzir os custos. Os anunciantes passaram a cobrar delas a mesma capacidade de adaptação às mudanças, não aceitando mais uma agência preocupada apenas com a propaganda isoladamente. Passaram a necessitar de um parceiro capaz de propor soluções de comunicação e co-responsável pelos resultados obtidos.

Hoje, as empresas demandam de suas agências acompanhamento desde a concepção do produto até sua divulgação, por meio de ações planejadas a médio e longo prazo, estudos e resoluções dos problemas de mercado, proposição de estratégias de comunicação e marketing e administração do processo de construção de marcas, que com o crescimento da concorrência, decorrente do aumento do número de produtos similares em oferta, tornou-se o principal ativo dos clientes.

Dessa forma, todas as ações de comunicação devem fazer parte de um plano com vistas a agregar valor à imagem de marca. Nenhuma ação pode ser pensada isoladamente. Isso tudo porque a exigência agora é por um plano de ações que seja, sim, criativo, mas sobretudo eficiente. "Hoje, as empresas querem da agência trabalhos cada vez mais criativos, mas fazem questão que as campanhas custem o mínimo possível em mídia, ao mesmo tempo que aumentem ao máximo suas vendas." (VALENTE, apud CIAFFONE, 2004, p. 22).

Daí a importância das agências de comunicação planejarem para seus clientes posicionamentos de mercado de maneira cada vez mais integrada, o que vai além da simples publicidade tradicional". "Das embalagens às notas fiscais, das novas cores da fábrica e dos caminhões aos uniformes dos funcionários, tudo passa pelo crivo de Nizan [Guanaes]." (BLECHER, 2003 , p. 46). Essa nova realidade significa um aumento significativo das funções e responsabilidades de uma agência para com seu anunciante, pois não basta mais só se preocupar com a publicidade, e sim com as diferentes formas de comunicação das empresas, numa sinergia entre as várias disciplinas da comunicação e de outras áreas de negócios.
1 Entende-se por comunicação integrada 0 conjunto de ações que incluem estratégias de no media, novas mídias, propaganda tradicional e todo o leque de possibilidades que visam agregar imagem institucional para as empresas por meio de ações de divulgação. 
Além do mais, assiste-se a uma revolução das tecnologias de comunicação e informação que trazem à tona um número cada vez maior de possibilidades de acesso aos consumidores. Isso num momento em que a segmentação do público torna-se cada vez maior, sendo necessários diferentes canais para se falar com os diversos nichos de mercado.

Segundo Kotler (1998), o mercado de massa foi segmentado, sendo necessárias ações de marketing específicas para cada público definido. O avanço da tecnologia trouxe inovações nas áreas de computação e informação que permitem um amplo conhecimento das demandas e desejos do consumidor, cada vez mais segmentado e individualizado.

$\mathrm{Na}$ esteira destas transformações o que se observa é que a propaganda tradicional está dando lugar a outros elementos do mix de promoção denominados no media ou no advertising ${ }^{2}$. Como exemplo podemos citar as diferentes formas de eventos, promoção, marketing direto, novas mídias, etc, que concorrem cada vez mais com as mídias tradicionais na distribuição da verba dos anunciantes. Tarsitano e Navacinsk (2005) mostram que, embora a propaganda ainda lidere os investimentos das empresas de comunicação, já se percebe um deslocamento importante para as demais ferramentas de marketing. Em 2005, por exemplo, a somatória dos investimentos em promoção, merchandising, eventos, marketing direto e Internet totalizou $40 \%$ de todo o investimento publicitário no Brasil.

Portanto, cabe ressaltar o ${ }^{2}$ Tudo aquilo que não é propaganda tradicional, mas que vende um produto, incluindo ações como promoçōes, patrocinio, marketing direto, novas mídias etc.
Em um momento em que os anunciantes têm como uma de suas prioridades a otimização de seus investimentos em comunicação, a opção por novas formas de mídias segmentadas torna-se bastante oportuna, uma vez que atendem melhor a estratégias direcionadas por um preço infinitamente menor do que o das mídias convencionais. Pode-se citar como exemplos de novas mídias: propaganda de cinema; jornais de bairro; mídias externas (busdoor, backbus, frontlights, empenas, painéis de metrô, painéis eletrônicos, protetores de árvore, publicidade em banca de jornais, bike-doors, publicidade em táxi, etc.); TV a cabo; Internet; celular, etc.

Isso não significa que as mídias tradicionais tenham deixado de ter um papel fundamental na divulgação de marcas de alcance (inter)nacional ou mesmo no lançamento de novos produtos. Apenas não se pode desconsiderar que, com a convergência digital, a tendência é que se reconfigurem de um modo bastante distinto do convencional, marcado pelo aumento significativo na qualidade das transmissões, pela multiplicação de canais e, sobretudo, pela ampliação dos tipos e números de serviços e conteúdos produzidos, como áudio, texto e imagens acessiveis por uma infinidade de meios digitalmente convergentes. Ou seja, com a convergência digital, cada mídia deixará de ocupar uma definição, lugar ou função estáticos ou preestabelecidos, em favor de novas e múltiplas possibilidades de como e o que transmitir, em termos de transmissão, e do quê, como e quando acessar, em termos de recepção.

Naturalmente, todo esse conjunto de transformações passa a exigir dos publicitários um perfil muito mais plural e generalista de atuação. Um 
profissional que saiba interpretar as mudanças nos cenários sociais e o modo como elas afetam a percepção de realidade dos consumidores, para só então traduzi-las em conceitos e posicionamentos de comunicação.

É o que vêm fazendo, por exemplo, os profissionais de planejamento da agência de publicidade Ogilvy, no que denominaram de era Butterfly ${ }^{3}$. Baseado na integração entre os diversos setores da agência, o modelo pretende partir da observação da realidade e das mudanças de comportamento do consumidor para a proposição de conceitos de criação de campanhas altamente integrados às ações de mídia, como vem sendo feito para a marca Dove, com o mote "Beleza real".

O interessante ê que esses modelos parecem instaurar uma mudança não só nos processos de criação e planejamento, mas na própria estrutura organizacional das agências. Pensar a comunicação de forma integrada também exige configurações adequadas dos fluxos de trabalho, tanto quanto da organização espacial. Prova disso é que a própria departamentalização das agências teve que ser revista nesse processo. Espaços físicos antes milimetricamente divididos vêm dando lugar, já há algum tempo, a áreas integradas de trabalho: grandes vãos sem paredes internas, por onde circulam profissionais das mais diferentes e múltiplas funções. Uma mudança que se pode observar não só nas principais agências brasileiras, como também nas internacionais.

E não é só nas configurações espaciais e de fluxos de trabalho que essas mudanças se apresentam, mas nos novos formatos de gestão de processos também. Inspirada na agência inglesa Mother, na holandesa Kessels Kramer e na americana Anomaly, a Fisher América $^{4}$, por exemplo, transferiu a função de atendimento para as áreas de planejamento $\mathrm{e}$ criação. Hoje, o que se valoriza é o trabalho integrado em que atendimento, planejamento, criação, mídia, produção gráfica e RTVC têm um papel estratégico fundamental, conforme vem sendo adotado pelas principais agências de publicidade em todo o mundo.

De fato, as tendências de alinhamento dos fluxos de trabalho em relação a modelos internacionalizados de gestão é um dos grandes desafios e também imposições de um modo de produção cada vez mais globalizado. Uma vez que as grandes agências vêm instaurando sedes próprias ou parcerias e fusões em todos os grandes centros do globo, a tendência é que os processos atravessem fronteiras e tornem o mundo da publicidade muito mais conectado.

Isso afeta diretamente as expectativas de desempenho empresarial das agências, que passam a competir com os demais escritórios internacionais, bem como a própria definição dos critérios de remuneração na publicidade. Se hoje é uma tendência das grandes empresas multinacionais serem atendidas por holdings ou conglomerados de comunicação, o caminho natural é que elas busquem uma maior padronização operacional no que diz respeito aos investimentos em publicidade, seja nos valores pagos às agências, seja no relacionamento com os fornecedores.

Para Comin (2005), isso aparece em dois aspectos fundamentais. Primeiramente, que as práticas
${ }^{3}$ Jornal Propaganda e Marketing, 23 de janeiro de 2006.

${ }^{4}$ Jornal Propaganda e Marketing, 16 de janeiro 2006. 
administrativas adotadas pelas grandes empresas, na medida em que divulgadas pela mídia e balanços sociais, tendem a influenciar ou contaminar as empresas menores, provocando uma reação em cadeia no mercado. Em segundo lugar, na medida em que cresce o controle legal e mesmo social sobre os balanços de empresas públicas ou privadas além, é claro, das exigêneias cada vez maiores por desempenho e rentabilidade, tende a crescer também a necessidade de uma maior transparência no modo como são aplicados os recursos em comunicação ou quaisquer outras áreas. A conseqüência disso estaria no aumento de processos de licitação e de concorrência para contratação de fornecedores ou mesmo no cadastramento cada vez mais detalhado dos mesmos, gerando a necessidade de normatizações e critérios sempre mais adequados às últimas exigências do mercado.

Dessa forma, isso faz com que seja necessária uma revisão do modo de se pensar e fazer publicidade, acarretando mudanças e adequações permanentes nas engrenagens $\mathrm{e}$ estruturas de sua cadeia produtiva.

0 conceito de cadeia produtiva aplicado ao novo cenário da Publicidade

Cadeia produtiva é o conjunto de todos os integrantes do processo produtivo em um determinado segmento ou setor da economia. As inter-relações entre os diversos agentes formadores da cadeia são chamadas de elos da cadeia. A noção de cadeia produtiva, portanto, compreende os agentes envolvidos na produção de um bem ou serviço.

De acordo com Proshnik e Vaz :

Uma cadeia produtiva é uma seqüência de setores econômicos, unidos entre si por relações significativas de compra e venda, na qual os produtos são crescentemente elaborados. As cadeias produtivas resultam da crescente divisão do trabalho $\mathrm{e}$ da maior interdependência entre os agentes econômicos. Por um lado, as cadeias são criadas pelo processo de desintegração vertical e especialização técnica e social. Por outro lado, as pressões competitivas por maior integração e coordenação entre as atividades, ao longo das cadeias, ampliam as articulações entre os agentes (...). (PROSHNIK e VAZ, 2006, p. 10)

O uso do conceito de cadeia produtiva permite: (1) visualizar a cadeia de modo integral; (2) identificar debilidades e potencialidades nos elos; (3) motivar articulação solidária dos elos; (4) identificar gargalos, elos faltantes e estrangulamentos; (5) identificar os elos dinâmicos, em adição à compreensão dos mercados, que trazem movimento às transações na cadeia produtiva; (6) identificar fatores e condicionantes da competitividade em cada segmento; e (7) poder perguntar a cada elo: está satisfeito com o elo para o qual vende? Está satisfeito com o elo do qual compra? ${ }^{5}$.

No âmbito da ciência econômica, o conceito de cadeia produtiva envolve uma discussão bastante abrangente em termos de conceitos e aplicações, embora restrita ao setor industrial. Nesse sentido, as cadeias de uma economia regional podem ser agregadas em conjuntos ou blocos, de forma que o valor médio das compras e vendas entre os setores constituintes de um bloco seja maior do que o valor médio das compras e vendas desses mesmos setores com os setores de outros blocos. Esses blocos são chamados de macrocadeias ou complexos 
industriais. Para os fins deste estudo, será utilizado simplesmente o termo cadeia produtiva para designar tanto as macroestruturas, quanto a cadeia mais localizada da Publicidade, foco dessa análise.

Os termos complexo industrial e cluster $^{6}$, muitas vezes usados como sinônimos de cadeia produtiva, parecem não se aplicar aos objetivos propostos por este estudo, uma vez que se referem ao contexto de competitividade nacional e internacional e têm sua aplicação voltada para o setor produtivo, especialmente o de grande porte. De acordo com Haguenauer e Prochnik, citados por Silva (2004, p.170), "um complexo industrial, por sua vez, é um conjunto de cadeias. Assim, as cadeias produtivas são partes dos complexos industriais [agrupamentos ou clusters]". Além disso, os complexos industriais apresentam como características: presença de uma indústria-chave; regime não concorrencial entre as várias indústrias existentes; e aglomeração territorial. Por outro lado, de acordo com Silva,

o modelo de cluster, na concepção de Michael Porter, de enfoque marcadamente empresarial e microeconômico, [é] caracterizado pela presença de grandes indústrias, de dimensão nacional e com elevada amplitude espacial e alto nível de agregação. (SILVA, 2004, p. 8)

Quanto às atividades de serviços, o conceito de cadeia produtiva, em seu sentido estrito, não as abrange porque as atividades de serviço consomem relativamente poucos produtos industriais. Assim, não se caracterizam, propriamente, cadeias de transformação. Mas, por outro lado, a análise de cadeias produtivas considera fortemente o papel das instituições. Esse aspecto é visível quando se tem em conta a diferença entre o conceito de cadeia e o alcance dos estudos sobre cadeias produtivas.

Enquanto o conceito de cadeia produtiva é bastante restrito, incluindo apenas a seqüência de atividades de transformação, os estudos sobre cadeias produtivas abordam todo o entorno delas, incluindo serviços especializados, organizações e programas governamentais, consumo, trabalho e instituições. Em particular, reconhecese tanto a relevância das organizações locais e das regras formais, quanto a das regras informais.

Assim, em muitos casos, observa-se a criação de instituições bilaterais ou coletivas que potencializam os efeitos para frente ou para trás. As parcerias entre empreșas e a organização de supply chain management $^{7}$ são formas de buscar ampliar os resultados da operação conjunta de empresas postadas ao longo das cadeias. Centros de pesquisa regionais, organizações de feiras de vendas de produtos e/ou de aquisição de insumos especializados e máquinas têm o mesmo efeito, aumentando a eficiência dos processos ou as vendas dos produtos finais. Enfim, há uma ampla variedade de iniciativas conjuntas que busca explorar as vantagens do esforço coletivo.

$\mathrm{O}$ conceito de cadeia produtiva aplicado ao campo da prestação de serviços em Publicidade e Propaganda tem funcionalidade técnica e eficácia heurística por buscar uma representação do processo produtivo como um todo integrado e dinâmico de partes que atuam sinergicamente, desde o fornecedor de matérias-primas, transporte, vendas, planejamento de estratégias, planejamento da produção, planejamento de mídia,

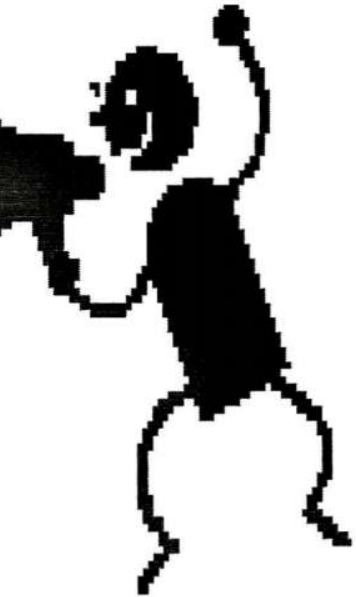

${ }^{6}$ Uma referência importante para tratar destes conceitos é o trabalho de PORTER, Michael. Competição: estratégias competitivas essenciais. 4. ed., Rio de Janeiro:Campus, 1999 ePORTER, Michael. A vantagem competitiva das naçōes. Rio de Janeiro: Campus, 1993. É possivel que nossos letores encontrem afinidades entre idéias aqui expostas e aquelas elaboradas por este autor, entretanto, não podemos fazer uma aplicação direta de seu modelo de análise pelos motivos expostos aaima.

70 termo suppply chain management em tradução livre pode ser lido como gestão da cadeia de suprimentos. Mas seu significado no campo da ciência da administração é bem mais amplo. Apresentada atualmentecomofundamental paraa vantagem competitiva das empresas, sugere que novas formas de relacionamento entre empresas e fornecedores sejam adotadas e passem a ser estruturadas por meio de vínculos de cooperação em contraposição à estruturação vertical por meio de vínculos decooperaçãohegemônica. Deacordo com estudo realizado por ABRAMCUK (2001, p. 12-13 ) sobre o tema, "a expressão 'cadeia de suprimento' é uma metáfora usada para descrever as empresas que estão ervolvidas no fornedimento de um produto ouserviço". Parafins desteestudo, importa reter da idéia de gestão da cadeia de suprimento que as relações de forneaimento implicadas na geração dos serviços publicatários podem dar mostras do grau de profissionalização e confiança que balizam estas mesmas relaçōes, tornando possivel observar se o mercado de trabahno em publididade de Minas, objeto empirico de pesquisa, está mais ou menos afinado com as transformaçōes eimpactos econômicos e sociais da atualidade. 


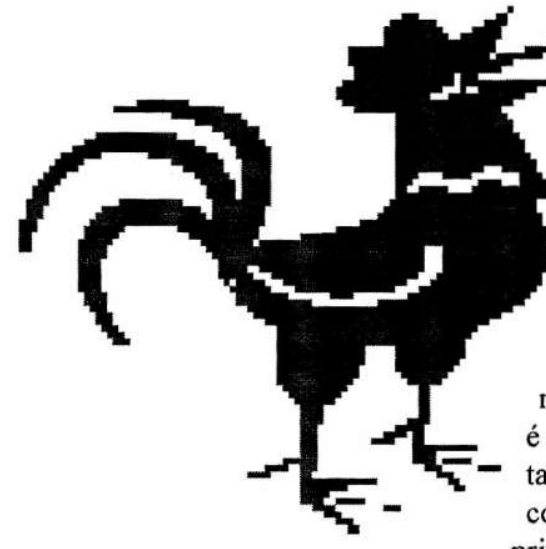
entidades ligadas à publicidade, com intuito primeiro de fidelizar os atuais clientes e, depois, de atrair outros novos.

No caso da publicidade, os primeiros elos são as agências, os fornecedores de produtos e serviços e os veículos de comunicação. Nas pontas da cadeia situam-se, por um lado, os anunciantes/clientes e, por outro, os consumidores.

A integração dos envolvidos busca a garantia da qualidade do produto final em termos dos requisitos do cliente - especificidades do seu segmento e objetivos estratégicos e sociais do seu negócio - excelência técnica, conformidade com os códigos de ética vigentes no setor e consonância com o contexto do consumidor alvo. A ausência de integração reduz a qualidade, encarece o preço dos produtos e dificulta, do ponto de vista logístico, o cumprimento de prazos e procedimentos acordados, diminuindo a competitividade e a inovação - fatores essenciais ao campo desse tipo de serviço.

É importante ressaltar que os elos da cadeia produtiva da publicidade são constituídos, obviamente, por empresas que desenvolvem atividades comerciais afins à publicidade. Entretanto, a posição ocupada por tais empresas, nos elos da cadeia produtiva, não é estática. É possível que num determinado projeto, uma mesma empresa ocupe a posição de veículo e, em outro, a posição de anunciante. Para exemplificar: dentro da cadeia produtiva, uma emissora de TV pode desenvolver sua função primordial de veicular, por meio de som e imagem, o conteúdo de um determinado anunciante e, nesse caso, ocupa a posição de veículo de comunicação. Porém, quando essa mesma emissora de TV tem uma demanda de comunicação e pretende fazer um trabalho de divulgação institucional ela pode contratar uma agência e, dessa vez, ocupa a posição de anunciante/cliente. E, quando a peça criada pela agência e produzida por um fornecedor for veiculada, a emissora de TV volta a ocupar seu lugar de veículo dentro da cadeia. Tornando, dessa forma, dinâmico o ciclo da cadeia produtiva da publicidade.

Com o objetivo de apontar os agentes envolvidos e sua atuação no processo de produção da Publicidade é preciso descrevê-los:

Anunciantes/clientes: são definidos como toda organização que apresenta a necessidade de comunicar alguma coisa para um determinado público. Geralmente, é de onde vem a demanda ou é apresentado o problema de comunicação. Segundo Lupetti (2003), existem os seguintes tipos de anunciantes: de bens de consumo, de serviços, de bens industriais, intermediários, de entretenimento, associações e governo. E completa:

Há no mercado empresas anunciantes dos mais diversos tipos, tamanhos e estruturas, desde pequenas empresas, grandes conglomerados internacionais, até empresas sem fins lucrativos e órgãos governamentais como 
empresas públicas ou mistas. Entre elas encontram-se empresas com estruturas organizacionais diferentes, por vezes simples, por vezes complexas e sofisticadas. (LUPETTI, 2003, p. 115)

Agências: são empresas prestadoras de serviços cuja finalidade é planejar estrategicamente a imagem de marca do anunciante, a partir da análise de mercados e suas oportunidades e da elaboração de projetos e planejamentos de comunicação que vão ao encontro de seus objetivos mercadológicos. Depois de definir o tipo de trabalho a ser desenvolvido, é responsabilidade da agência indicar os fornecedores mais compatíveis em termos de qualidade, prazo e preço, além de acompanhar todo o processo produtivo até o final com vistas a garantir o melhor resultado para todos os envolvidos. Para Borges (2002):

Agência de propaganda. Pessoa jurídica independente, especializada na arte e técnicas publicitárias, que estuda, planeja, concebe e executa publicidade e material promocional; avalia, seleciona e programa os veículos de divulgação, por ordem e conta de clientesanunciantes... (BORGES, 2002, p. 211)

Fornecedores: são as empresas e profissionais que executam os produtos de comunicação propostos pela agência para um determinado cliente. Para Lupetti (2003), os fornecedores de uma agência são: gráficas, birôs, fotógrafos, empresas de bancos de imagens digitais, produtoras de áudio, de vídeo, agências de modelo, institutos de pesquisa (de mercado, de comunicação e de mídia), além de muitas outras empresas que prestam serviços ou vendem seus produtos para que as agências possam desenvolver seus trabalhos de forma eficiente e eficaz com o retorno positivo para seus clientes. E conclui:

...é o caso das empresas que oferecem serviços de montagem de estandes, confecção de brindes e tantos outros cujo envolvimento da agência não é tão complexo, implicando levantamento de orçamento, aprovação, amostras, acompanhamento, entrega, recebimento e distribuição. (LUPETTT, 2003, p.135)

Veículos: São as empresas responsáveis por transmitir a mensagem, ou seja, as peças publicitárias produzidas pelas agências e devidamente aprovadas pelo cliente nos meios de comunicação tradicionais e contemporâneos para o consumidor final. Segundo Sant'anna (1996), tais meios são definidos como mídia impressa e mídia eletrônica e podem ser classificados em: a) meios visuais (para serem lidos ou vistos); b) meios auditivos (para serem ouvidos); c) meios audiovisuais (para serem lidos, ouvidos e vistos); d) meios funcionais (para desempenhar uma determinada função).

Consumidores do produto e da publicidade: eles fazem parte da cadeia produtiva e estão na ponta do processo de distribuição de um determinado produto ou de uma prestação de serviço. $\mathrm{Na}$ cadeia produtiva, são decisivos no processo de compra e é para eles que estão dirigidas as mensagens sob a forma de produtos, serviços e a própria publicidade. Segundo o Dicionário da Comunicação (2002), é possível classificar os consumidores em três categorias, levando em conta a freqüência de compra: a) heavy users ou compradores freqüentes e fiéis de 
um produto ou serviço; b) médium users ou consumidores médios e $\mathrm{c}$ ) light users ou consumidores eventuais e esporádicos.

Vale dizer que tanto no ambiente institucional (cultura, educação, tradição, legislação etc), quanto no ambiente organizacional (associações, sindicatos, políticas e incentivos que influenciam as atividades do setor etc), a governança e o capital social são fundamentais para ampliação da interdependência entre os elos, bem como, para aumento da confiança interna.

Governança é, acima de tudo, uma prática gerencial, administrativa, que compreende, numa estrutura orgânica de participação, os diversos interesses e enfoques, vindos dos acionistas, dos assalariados, dos clientes, dos fornecedores e da comunidade, que pode ser afetada por questões de segurança, de emprego e de meio ambiente.

No âmbito de um setor econômico, como é o caso da Publicidade, percebe-se que a adoção de princípios de governança - tanto em nível corporativo, ou seja, pensando-se a lógica interna das empresas que o compõem, quanto em nível da cadeia produtiva, ou seja, pensando-se a integração externa destas empresas numa dinâmica de relacionamentos - torna-se capital para o seu desenvolvimento.

Se o conceito de governança é importante para o entendimento ou, no mínimo, a reflexão sobre o ambiente organizacional no qual se desenha a cadeia produtiva, o conceito de capital social, por outro lado, é de suma importância para compreender as inter-relações internas a ela em termos de ambiente institucional. Este determinará vocações e predisposições e compreendê-lo, estimulálo é também uma forma de pensar estratégias de desenvolvimento.

Para Kliksberg (1999), os especialistas e as agências multilaterais reconhecem, de forma geral, três formas de capital, ou seja, três formas de ativos que produzem riqueza e desenvolvimento: a) o capital físico natural, constituído pelos recursos naturais de um país; b) o capital construído pelo homem, que inclui a infra-estrutura, o capital financeiro, comercial etc.; c) o capital humano, incluído nos anos 19701980 , referindo-se às habilidades, conhecimentos e criatividade com que os indivíduos contribuem para a vida econômica.

Mais recentemente, voltou-se o foco para o potencial de produção de riqueza e desenvolvimento, que flui das várias formas de associação coletiva: o capital social. Esse capital refere-se aos laços de confiança, de compromisso, de vínculos de reciprocidade, cooperação e solidariedade, capazes de estimular normas, contatos sociais e iniciativas de pessoas para aumentar o desenvolvimento humano e econômico.

Trabalhar com o conceito de capital social é desafiador, pois engloba outros, tais como, "confiança", "solidariedade" e "redes". O desafio aumenta quando a questão de medir não está apenas na quantidade, mas também na qualidade de capital social em variadas escalas.

A proposta é verificar, a seguir, ainda que parcialmente, o grau de amadurecimento do capital social e da governança na cadeia produtiva da publicidade mineira, mapeando as ações das entidades representativas do setor, no sentido de promovê-los em seu ambiente organizacional e institucional.

0 mercado publicitário mineiro e suas contribuições: esforços institucionais e de mercado

Ainda são tímidas, se comparadas com as ações do eixo São Paulo e Rio 
de Janeiro, as propostas do mercado mineiro no que diz respeito a novas posturas e ações efetivas que provoquem e estimulem reflexões sobre o fazer publicitário com o objetivo de profissionalizar e alavancar o setor.

Os dados do $\mathrm{CENP}^{8}$ apontam que $60 \%$ das empresas certificadas pela instituição encontram-se na região sudeste, sabidamente o principal pólo industrial e financeiro do Brasil e que, conseqüentemente, abriga o maior número de veículos e fornecedores de comunicação. Mesmo estando nessa região privilegiada, em 2005, os investimentos de publicidade em Minas representaram apenas $4 \%$ dos $\mathrm{R} \$ 34.469 .048,00^{9}$ investidos no País. Desse total, $37 \%$ foram capitalizados pela cidade de São Paulo, $14 \%$ pela cidade do Rio de Janeiro, $8 \%$ pelo interior de SP e o restante diluído por 8 regiões.

Em uma outra sondagem feita pelo SEBRAE ${ }^{10}$ tem-se um retrato do mercado mineiro de novembro de 2004 a fevereiro de 2005. Em um universo de 377 agências entrevistadas, pelo menos $41 \%$ não são certificadas pelo CENP. Esse dado torna-se mais expressivo quando percebe-se que $29,6 \%$ desse universo possui mais de 10 funcionários, 5,9\% têm de 21 a 50 funcionários e apenas $2 \%$ possuem mais de 50 funcionários. Portanto, as características do universo mineiro apontam para uma realidade em que $60 \%$ das empresas de médio e grande porte possuem até 9 funcionários. Na caracterização de porte, tem-se um mercado dominado pelas micros e pequenas empresas, $69,4 \%$ e $21,2 \%$, respectivamente. Do total, apenas $4,7 \%$ são consideradas médias e $2,8 \%$ grandes.

Quanto à produção, percebe-se que as empresas mineiras se esforçam para oferecer o maior número de serviços possível. Mais de $80 \%$ oferecem a criação de campanhas publicitárias, planejamento de marketing e propaganda, desenvolvimento de logomarca, criação de anúncios para revistas, placas de outdoor, seleção e contratação de veículos de mídia bem como produtos de design. Ao serem questionadas sobre o principal produto, $36,6 \%$ definem a produção de campanha, $9,8 \%$ elegem o desenvolvimento de planejamento de marketing e propaganda, $7,2 \%$ falam de produtos de design. As demais opções são diluídas em

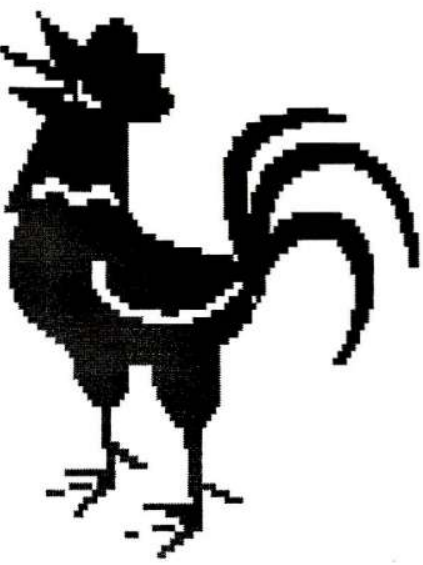
pequenos percentuais.

Em relação ao número de clientes, $29,2 \%$ dizem possuir uma carteira com volume entre 6 e 10 . Em torno de $26 \%$ disseram ter entre 11 e 20 clientes registrados. Já $28,1 \%$ afirmaram ter uma carteira com mais de 20 clientes. Das pequenas empresas, $36,3 \%$ trabalham com mais de 20 clientes. O mesmo acontece com as grandes, já num percentual bem maior, $66,6 \%$ do total.

Quanto à representatividade financeira do principal cliente, é possível perceber uma relação de dependência significativa; $55,6 \%$ das grandes empresas afirmaram que o principal cliente representa em média de 21 a $50 \%$ do faturamento, um percentual bastante expressivo para uma empresa de grande porte. Dentre as pequenas, $5 \%$ afirmaram que essa relação é da ordem de mais de $80 \%$, o que significa dizer que a ausência ou estagnação desse cliente pode implicar no fechamento da empresa. Esses clientes vêm dos setores de serviço e comércio, enquanto a indústria representa apenas $16,4 \%$ desse universo.

Chama a atenção, no caso das grandes empresas, a divisão quase que proporcional entre os segmentos de serviços e governo, $44,4 \%$ e $55,6 \%$, respectivamente. Em relação à área de
${ }^{8}$ Conselho Executivo das NormasPadrão. Instituído em 1998, é uma entidade criada pelo mercado publicitário para fazer cumprir as Normas Padrão de Atividade Publicitária, documento básico que define as condutas e regras das práticas éticas e comercias entre os principais agentes da publicidade brasileira. Disponivel em http:// uww.cenp.com.br

${ }^{9}$ http://www.sindapro-mg.com.br/ briefing/2006-02-24.htm.

${ }^{10}$ Diagnóstico do Mercado Mineiro de Propaganda. Pesquisa realizada pela Fundação João Pinheiro entre os meses de novembro de 2004 e fevereiro de 2005 e editada em maio de 2005. Iniciativa do SEBRAE-MG em parceria com nove entidades de dasse de Minas Gerais. 


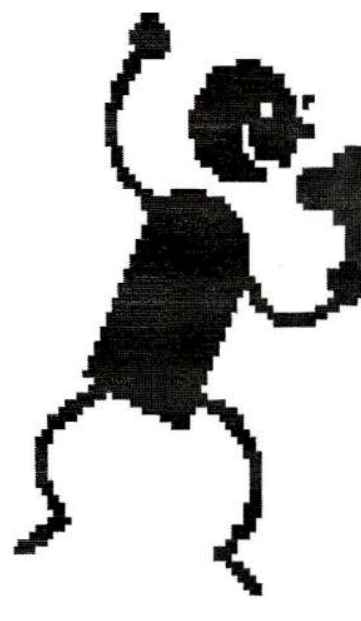

atuação, $41 \%$ das entrevistadas têm atuação em Minas e em outros estados. Desse universo, $100 \%$ no caso das grandes empresas e $72,2 \%$ no caso das médias.

O processo de informação ainda padece de verbas. A pesquisa mostra que apenas $44,4 \%$ das grandes agências contratam os serviços do IBOPE (mídia). Esse percentual cai para $38,9 \%$ no caso das empresas de médio porte. Apesar de terem a Internet como fonte de informação, $38,9 \%$ das agências de médio porte ainda não possuem um site ativo e o mesmo acontece com $11 \%$ das grandes empresas entrevistadas.

A comissão de veiculação continua sendo a principal forma de remuneração para as grandes empresas. Nenhuma delas trabalha por resultado e o maior percentual dessa modalidade de remuneração, $16,7 \%$, aparece no grupo das empresas de médio porte.

O tempo de atuação da maioria das agências é, em média, de 10 anos para $55 \%$ das empresas entrevistadas e de cerca de 30 anos para pouco mais de $10 \%$ delas. A pesquisa mostra também que o mercado de Minas ainda não conseguiu equacionar a tríade qualidade/preço/ prazo. Permanece a cobrança por uma melhor relação custo/benefício sem, no entanto, considerar investimentos. Os principais desafios relatados pelos entrevistados basicamente se dividem entre questões de ordem financeira e cultura local. Da mesma forma, a concorrência desleal, a falta de fidelidade dos fornecedores e a dificuldade de se estabelecer padrões de preço demonstram um distanciamento da classe. Os entrevistados revelam ainda a necessidade de maior fiscalização do setor, mais transparência e ética nas relações estabelecidas e maior investimento em linhas de crédito.

Poucos esforços são percebidos no sentido de intensificar o corporativismo na área. As duas principais entidades do setor em Minas, a AMP ${ }^{11}$ e o SINAPRO ${ }^{12}$, articulam ações e parcerias com diferentes setores da economia, como o documento Acorda Minas e - Projeto de Revitalização da Indústria da Comunicação. No primeiro, a ABAP se uniu a outras 17 entidades do setor no Estado, entre elas AMP e SINAPRO, e encaminhou uma carta-documento ao Governo de Minas. $O$ documento registra números e fatos significativos sobre as particularidades do mercado mineiro com vistas a sensibilizar o poder público e convidá-lo a fazer um pacto para juntos promoverem uma política de comunicação estratégica para a construção da "marca Minas". O Projeto de Revitalização da Indústria da Comunicação é encampado pelo SEBRAE-MG com outros 10 parceiros, entre eles a ABAP e o SINAPRO. O projeto descreve objetivos e estratégias para a profissionalização do setor e propõe um diagnóstico setorial por meio de pesquisa a ser realizada no mercado mineiro (que até a presente data ainda não foi disponibilizada).

Fundada em 1957, a Associação Mineira de Propaganda - AMP - tem como principais ações o prêmio Profissionais do Ano, já na sua $25^{a}$ edição, responsável por premiar os melhores trabalhos da publicidade mineira e o CRIAFEST, Festival de Criação Universitária, em parceria com o Clube de Criação de Minas CCPM -, em sua $3^{\text {a }}$ edição, que premia os melhores trabalhos desenvolvidos por universitários. Também o Prêmio do CCPM, em sua $8^{a}$ edição, é um outro esforço de 
expressão cujo objetivo é a produção do Anuário de Criação Publicitária de Minas Gerais. A premiação é reconhecida pela comunidade mineira e envolve profissionais de outros estados.

O capítulo mineiro da Associação Brasileira da Indústria Gráfica - ABIGRAF - MG - e o Sindicato das Indústrias Gráficas de MG, mediante parceria, lançaram, em 2005, o Prêmio Mineiro de Excelência Gráfica Cícero. Em sua segunda edição, o prêmio é uma tentativa de valorização da produção gráfica mineira e de interlocução entre agências e outros integrantes do processo de produção gráfica. $\mathrm{O}$ mercado conta com outras entidades que, apesar de realizarem trabalhos de governança corporativa, têm uma atuação restrita.

\section{Considerações finais}

Os dados sobre a publicidade mineira apontam especialmente para o modo como as agências vêm atuando e estruturando seus modelos de negócio. Tais dados indicam, sobretudo, que os investimentos em publicidade no Estado, o grau de profissionalização e as articulações institucionais são ainda incipientes, muito longe do quevem sendo praticado, em termos de movimentação de recursos, know-how e corporativismo em mercados como São Paulo e Rio de Janeiro.

Nesses mercados, observa-se que $o$ alto volume de recursos investidos pelos anunciantes, a exigência por qualidade dos serviços e, conseqüentemente, por profissionalismo, são simultâneos. Ou seja, um modelo peculiar de fluxo e conexão entre os diversos agentes envolvidos no processo da comunicação é estabelecido: anunciantes exigem maior qualidade e alcance dos serviços publicitários e melhor performance dos profissionais, que por sua vez cobram o mesmo desempenho dos outros agentes do processo, como fornecedores e veículos de comunicação. Trata-se de um fluxo em cadeia, aqui tomado pelo modelo de estudo das cadeias produtivas, conceito norteador do objeto de reflexão da presente pesquisa.

Tomar como referencial o conceito de cadeia produtiva nos possibilita a proposição de um outro desenho de fluxo para o mercado mineiro: num sentido inverso, pensar que quanto maior a profissionalização, maiores os índices de qualidade dos serviços oferecidos e, conseqüentemente, as possibilidades de disputar recursos, aumentando a movimentação financeira em publicidade no Estado. Em outras palavras, adotar o modelo de cadeia produtiva como referencial de profissionalização e gestão do negócio da publicidade em Minas Gerais, por meio de fomentos institucionais, pode fazer com que o mercado torne-se, paulatinamente, mais apto a competir em nível nacional e internacional.

Por ora, os dados mostram que o mercado de publicidade mineiro é ainda muito endógeno, pois seus agentes pensam e operam nele a partir de preocupações e demandas muito isoladas e pontuais. Essa visão mostra uma percepção da publicidade muito pouco conectada às configurações globais dos cenários político, econômico e social da contemporaneidade que, conforme apresentado anteriormente, têm instaurado modelos de negócio cada vez mais globais.

$\mathrm{Se}$, por um lado, os dados sobre o mercado publicitário mineiro parecem um pouco alarmantes, por outro já se pode observar pequenos esforços indicativos de uma nova preocupação: articular os diversos agentes da cadeia produtiva da publicidade, em Minas Gerais, por 
meio de iniciativas de governança. Ações cujo objetivo é reunir os diversos interesses e enfoques do segmento tanto em nível corporativo, quanto em nível da cadeia produtiva, afim de, pela integração interna e externa dos agentes envolvidos, promover o desenvolvimento do setor.

\section{Abstract}

With the intensified processes of globalization since the beginning of the 90 's, Advertising has undergone profound transformation, generated by social, political, economic and cultural changes in the country, revealing at present a scenario with very particular business-oriented strategies. In this overview, the concept of "productive chain" is presented in order to establish the inter-relationship among a multiplicity of factors involved in executive advertising production. The objectives of this article are to contextualize these recent transformations in national advertising, to present the use of the concept of "productive chain" and its contributions to executive advertising, in addition to showing the institutional actions and markets that Minas Gerais can carry forward while adjusting to the new era of advertising in Brazil and the world.

Keywords: Advertising; Publicity; Executive Market Advertising; Productive Chain; Minas Gerais Advertising.

\section{Referência}

ABAP. Disponivel em: <http:// ww.abap.org.br> Acesso em 19 mar. 2006. AMP. Disponivel em: <http://www.amppropagandamineira.com.br $>$ Acesso em 16 maio 2006.

ABRAMCZUK, André Ambrosio. Os Relacionamentos na Cadeia de Suprimento sob o Paradigma da Desintegração Vertical de Processos: Um Estudo de Caso. Dissertação de Mestrado apresentada à Escola Politécnica da Universidade de São Paulo. São Paulo, 2001. Disponível em <http:// www.teses.usp.br> Acesso em 05 mar. 2006 BORGES, Admir Roberto. 0 executivo de contas publicitárias. Belo Horizonte: $\mathrm{FCH} /$ FUMEC, 2002.
BLECHER, Nelson. Bem-vindo à propaganda de resultados. Revista Exame. São Paulo, n.24, p. 44-58, nov. 2003.

CENP. Disponivel em: <http:// ww.cenp.com.br> Acesso em 21 abr. 2006. CIAFFONE, Andréa. Na mente dos consumidores.' Revista Forbes. São Paulo, n.98, p. 18-28, out. 2004.

COMIM, Arnaldo. Cartas na mesa. Revista Meio\&Mensagem. São Paulo, n. 1179, p. 28, out. 2005.

IBOPE MONITOR. Disponivel em <http:// www.sindapro-mg.com.br/briefing/2006-0224.htm> Acesso em 10 de maio de 2006.

KLIKSBERG, Bernardo. Capital social y cultura: claves esenciales del desarrollo. Revista de la CEPAL, Santiago de Chile, v. 69, p. 85-112, dec. 1999.

KOTLER, Philipe. 0 desafio de criar experiências. HSM Management: Informação e Conhecimento para a Gestão Empresarial. São Paulo, n.7, p. 94-99, mar.-abr. 1998. LUPETTI, Marcélia. Administração em Publicidade: a verdadeira alma do negócio. São Paulo: Pioneira, 2003.

MACEDO, Paulo. Fisher elimina atendimento. Jornal Propaganda e Marketing, São Paulo, n. 2088, p.5, jan. 2006.

. JWT une criação e mídia. Jornal Propaganda e Marketing, São Paulo, n. 2088, p.5, jan. 2006.

. Planejamento da Ogilvy entra na era Butterfly. Jornal Propaganda e Marketing, São Paulo, n.2089, p.22 , jan. 2006.

MINISTÉRIO DO DESENVOLVIMENTO, INDÚSTRIA E COMÉRCIO EXTERIOR. Disponivel em <http:// www.desenvolvimento.gov.br/arquivo/sdp/ forCompetitividade/doBasmetodologia.doc> Acesso em 05 mar. 2006.

PROCHNIK, Victor e VAZ, Bruno Ottoni. "Cadeias Produtivas do Estado de Minas Gerais". Disponivel em <http://www.ie.ufrj.br/ cadeiasprodutivas/index.html > Acesso em 05 mar. 2006.

RABAÇA, Carlos Alberto \& BARBOSA, Gustavo Guimarães. Dicionário de comunicação. Rio de Janeiro: Campus, 2001.

SANT'ANNA, Armando. Propaganda: teoria, técnica e prática. 6 ed. São Paulo: Pioneira, 1996.

SILVA, Jorge Antonio Santos. Turismo, crescimento e desenvolvimento: uma análise urbanoregional baseada em cluster. 2004. Tese (Doutorado) - Escola de Comunicações e Artes/ USP. Disponivel em <http://www.eumed.net/ 
Metamorfose de uma nova publicidade. In SINAPRO. Disponivel em <http://www.sindapromg.com.br> Acesso em 21 abr. 2006. Congresso Brasileiro de Ciências da

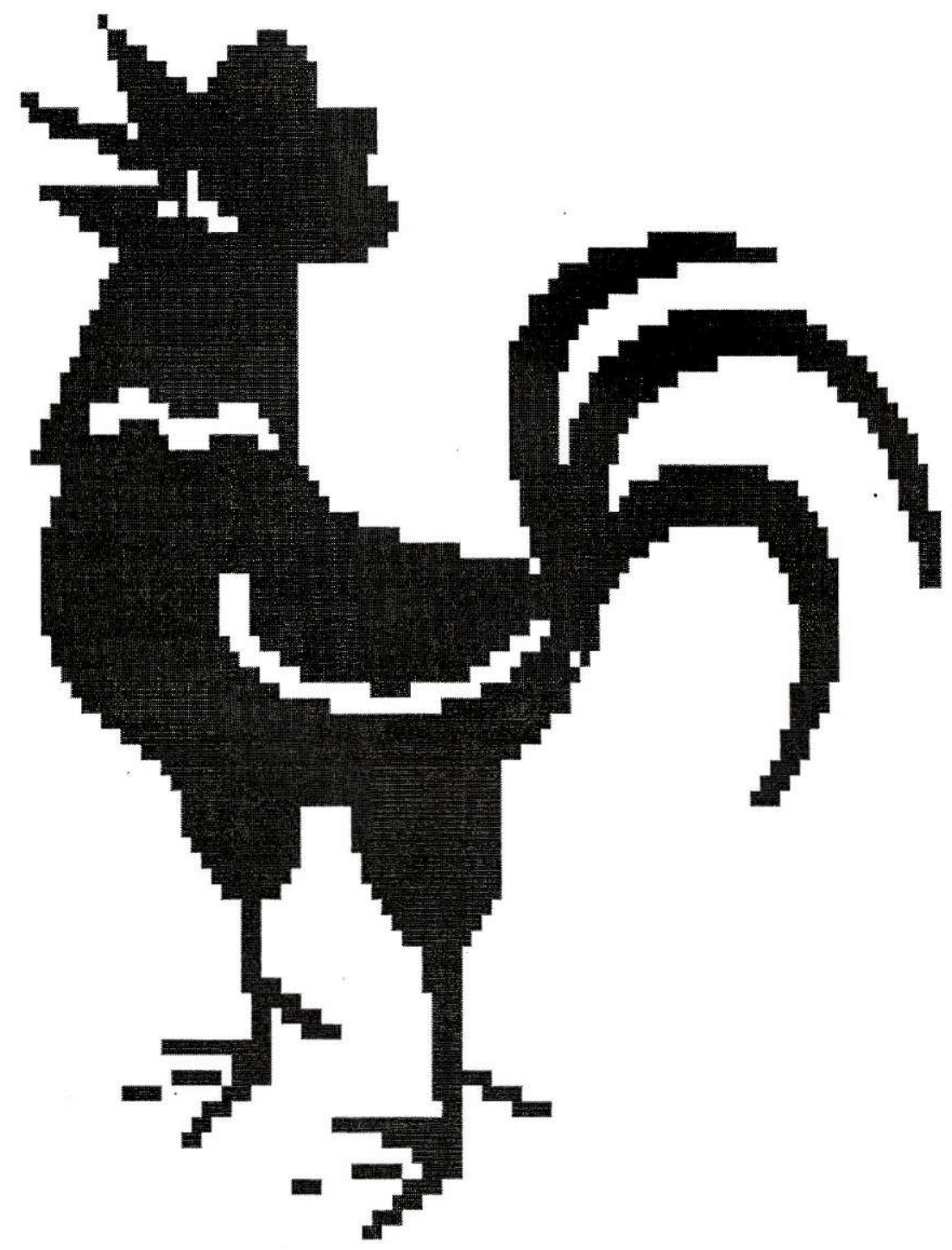

Data do recebimento: 20/07/2006

Data do aceite: 18/08/2006 aplicado ao mercado mineiro. Comunicação \& Informação, V 9, nº 2: pág 164 - 177 - jul/dez. 2006. 